\title{
Case Report \\ Hemoperitoneum in a Cirrhotic Patient Due to Rupture of Retroperitoneal Varix
}

\author{
Igor Rafael Sincos, ${ }^{1,2}$ Grace Mulatti, ${ }^{1}$ Sheila Mulatti, ${ }^{1}$ Ilana Cristina Sincos, ${ }^{1}$ \\ Sergio Q. Belczak, ${ }^{1}$ and Valdir Zamboni ${ }^{1}$
${ }^{1}$ Department of General Surgery of Universitary Hospital and Clinics Hospital, University of São Paulo Medical School (FMUSP), 05403-000 São Paulo, SP, Brazil
${ }^{2}$ Section of Vascular Surgery, Clinics Hospital, University of São Paulo Medical School (FMUSP), Avienda Dr. Enéas de Carvalho Aguiar 255, 05403-000 São Paulo, SP, Brazil

Correspondence should be addressed to Igor Rafael Sincos, igorsincos@gmail.com

Received 7 May 2008; Revised 7 October 2008; Accepted 3 February 2009

Recommended by Richard Charnley

\begin{abstract}
The rupture of retroperitoneal varices is a rare and catastrophic complication of portal hypertension. We describe a case of this nature, the first in Brazilian medical literature, and also reviewing all previous 34 cases. We systematically analyzed all therapeutic approach and propose a management algorithm for diagnosis and treatment of this lethal condition. The majority of the patients presented with abdominal pain, distention and hypotension, and developed hemorrhagic shock. Rupture of retroperitoneal varices can be properly managed if an early diagnosis is made and surgery is performed promptly, which is the only effective treatment. Arteriography should be used when the suspicion is of rupture of hepatocellular carcinoma.
\end{abstract}

Copyright (C) 2009 Igor Rafael Sincos et al. This is an open access article distributed under the Creative Commons Attribution License, which permits unrestricted use, distribution, and reproduction in any medium, provided the original work is properly cited.

\section{Introduction}

The first case of rupture of retroperitoneal varices, a rare and catastrophic complication of portal hypertension, has been reported in 1958 [1]. According to our research over Medline and PubMed, to date, only 34 similar cases have been described with high mortality rates even nowadays [1-38]. We used hemoperitoneum and varices as keywords for search. The aim of this article is to describe a case of this nature, the first in Brazilian medical literature, and also reviewing all previous cases. We systematically analyzed all therapeutic approaches and propose a management algorithm for diagnosis and treatment of this lethal condition. Rupture of retroperitoneal varices can be properly managed if an early diagnosis is made and surgery is performed promptly.

\section{Case Report}

A 51-year-old woman entered the Emergency Department of Universitary Hospital of the University of Sao Paulo (USP) in March 2006 presenting with abdominal pain for two days, associated with nausea and vomits. She also reported abdominal distention for the last fourteen days.

Her past medical history showed a chronic abuse of alcohol leading to liver cirrhosis associated to Hepatitis B. She had been under medical follow-up with a clinician from 2001 to 2004, when she abandoned medical care.

Her physical examination was remarkable for an illappearing, pale, jaundiced, and dyspneic patient. She had a heart rate of 100 beats/min and a systolic blood pressure of 95 and diastolic of $65 \mathrm{~mm} \mathrm{Hg}$. Abdominal examination revealed diminished bowel sounds, a slight distention, and diffuse tenderness during palpation, with no guarding. Admission laboratory values showed hemoglobin level of $6.4 \mathrm{~g} / \mathrm{dL}$. MELD score of 24, Child-Pugh grade C.

An endoscopy was carried out, which showed a healed distal esophageal ulcer, a hiatal hernia, and erosive gastritis of the body and antrum. There were no signs of esophageal varices.

A few hours after entering the Emergency Department she developed severe hypotension of 70/40 $\mathrm{mm} \mathrm{Hg}$, Glasgow 
coma scale 14 , tachycardia of 125 beats/min. She underwent volume resuscitation with no sustained response. Treatment for Spontaneous Bacterial Peritonitis was initiated with Ceftriaxone. Additional treatment with norepinephrine was started as she remained hypotensive even after the continuous infusion of volume. She was then transferred to the intensive care unit. She had progressive hemodynamic instability, abdominal distention, and altered mental status, requiring endotracheal intubation.

At this time a surgeon was requested to examine the patient. A paracentesis was carried out; the peritoneal fluid was hemorrhagic with a hematocrit of $12 \%$. Laboratory values at this moment were hemoglobin level of 3.8 and INR of 7.29. She was then transfused with packed RBCs and plasma. Reaching hemodynamic stability she underwent an exploratory laparotomy.

About $5 \mathrm{~L}$ of blood were evacuated from the peritoneal cavity. A ruptured retroperitoneal varix was found to be the cause of bleeding, next to the mesenteric root. Direct ligation of the vessel led the bleeding to stop (Figure 1). The liver was cirrhotic; an exuberant collateral circulation was seen on the retroperitoneum and on the abdominal wall, with canalization of the Umbilical vein, with an $8 \mathrm{~mm}$ diameter. The Retzius vein was identified in both paracolic gutters, with a lot of collaterals. A liver biopsy was made. Later histopathological evaluation revealed steatohepatitis grade IV (alcoholic and nonalcoholic).

Returning to the intensive care unit the patient was massively transfused with packed RBCs and plasma for anemia and coagulopathy. She continued to be hemodynamically unstable associated with renal and hepatic failure. On the sixth posoperatory she died of multiple organ dysfunction syndrome.

\section{Discussion}

Trauma and nonmalignant gynecological conditions account for more than $90 \%$ of intraperitoneal hemorrhages [2]. The main cause of hemoperitoneum in women is the rupture of an ectopic pregnancy; in men, the major cause is the posttraumatic rupture of the liver or spleen [2]. The vascular causes are also relevant, as the Aorta Aneurysm, rupture of viscera, and hemorrhagic pancreatitis. Inflammatory and hematological disorders rarely manifest as hemoperitoneum.

In cirrhotic patients with ascites the intraperitoneal bleeding occurs most of the times due to structural lesions such as hepatocellular carcinoma or ovary cancer and rupture of intraperitoneal varices [3].

The intraperitoneal varices rupture is a rare event, whose incidence unknown, and it is related to severe portal hypertension. We believe that the real incidence of this pathology is much superior than the 34 cases described in literature due to misdiagnosis. It also appears in patients with terminal liver disease, mostly in a fulminate way.

Portal hypertension leads to the development of portosystemic shunts in well-defined anatomic sites. The most acknowledged sites include the gastroesophageal veins connecting the azigohemiazigos system, the hemorrhoidary
TABle 1: Summary of Presentation, Management and Results of all 35 cases.

\begin{tabular}{lc}
\hline Patients $n$ : $35(\%)$ & \\
\hline Signs and symptoms & $24(68.6 \%)$ \\
Hypotension or shock & $23(65.7 \%)$ \\
Abdominal pain & $15(42.8 \%)$ \\
Abdominal distention & \\
\hline Diagnosis & $22(62.8 \%)$ \\
Paracentesis & $6(17.1 \%)$ \\
Arteriography & $7(20 \%)$ \\
\hline Source of bleeding* & $6(17.1 \%)$ \\
Umbilical veins & $5(14.3 \%)$ \\
Retzius veins & $19(54.2 \%)$ \\
Retroperitoneal varices & \\
Other intraperitoneal sources & $27(77.1 \%)$ \\
\hline Treatment $\#$ & $6(17.1 \%)$ \\
Variceal or vein ligation & $3(8.6 \%)$ \\
Clinical management & $1(2.8 \%)$ \\
Portocaval shunt & $23(65,7 \%)$ \\
Arteriography (embolization) & $12(34,3 \%)$ \\
\hline Outcome & \\
Death & \\
Survival & \\
* Some patients had more than one source of bleeding. & \\
\#Some patients were submitted to more than one treatment. & \\
& \\
& \\
&
\end{tabular}

veins from the inferior mesenteric vein, communicating with the tributaries of the Internal Iliac Vein and the Umbilical and periumbilical veins draining to the left Portal Vein and to the epigastric veins of the anterior abdominal wall. The recanalization of the Umbilical vein is known as CruveillierBaumgarten Syndrome $[1,4]$. There are also shunts of the Retzius veins connecting the Colic veins with the lumbar and the lower intercostals veins; pancreatic veins connecting the splenic vein and the left renal vein; numerous venous canals communicating the liver with the diaphragm (Sappey veins) [1].

There are 34 cases of intraperitoneal bleeding due to rupture of varices described in literature, as shown in Table 1. Including our patient, 27 were men and 8 were women. The age onset was 21 to 76 years old (average of 48.8). Only one case reported in literature was of a noncirrhotic patient. Table 1 summarizes the presentation, diagnosis, treatment, and results of the cases described in literature.

The majority of the patients presented with abdominal pain, distention and hypotension, and developed hemorrhagic shock. The diagnosis was established by paracentesis, angiography, ultrasound Doppler, and tomography. Even so, the diagnosis was confirmed only by laparotomy.

The hemoperitoneum diagnosis is confirmed by paracentesis when the $\mathrm{Ht}>5 \%$. The paracentesis was important in the diagnosis and surgical indication is most of the cases. Only two cases out of ten who survived did not undergo 


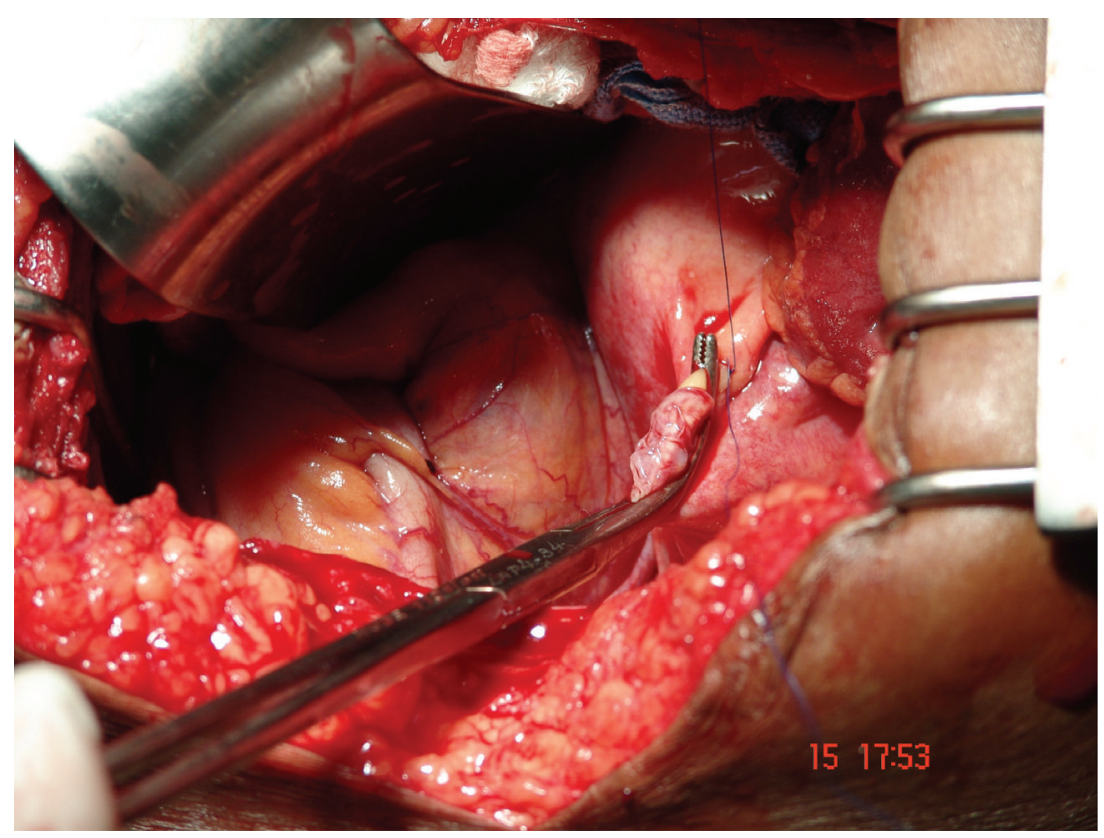

FIGURE 1: Direct ligation of the vessel in retroperitoneum.

the paracentesis $[5,6]$. In one of them, the diagnosis was suggested via tomography and confirmed at laparotomy [5].

The angiography was used as an attempt to achieve the diagnosis in 6 cases of hemoperitoneum by varices inside the abdomen [7-12]. The source of the bleeding was identified only in one patient. However, this patient past away probably because of recurrent bleeding [8]. In one case the angiogram may have anticipated the recurrent bleeding and finally his death [9].

The only effective treatment was surgery. None of the 7 patients treated in a nonchirurgical basis survived. Twenty eight were operated, twelve survived. The global mortality rate was $65.7 \%$. And for the patients submitted to surgery it was of $57.1 \%$. The causes leading of death were uncontrollable or recurrent bleeding, liver failure, kidney failure, heart failure, and aspiration of blood from ruptured esophageal varices.

Out of 28 cases that underwent surgery, in twenty six the ligation of the bleeding vessels was successful, and eleven survived the after surgery period. In two cases who underwent surgery, the ligation was not possible [12, 13], and the patient died of bleeding, even after the use of a portocaval shunt as an attemptive to relieve the portal hypertension [12]. Only one patient survived after a porto-systemic shunt [14].

The management of the bleeding from intra-abdominal varices is difficult since there are no randomized trials due to the rareness of this situation [15]. However, this condition seems to be underestimated, probably because most of the patients present tense ascitis and hepatic disease in a terminal state leading rapidly to death [2].

The patients' survival rate seems to be related to three important facts: the patient's functional hepatic reserve, the importance of the hemorrhagic shock in its presentation, and the early operative intervention and control of the bleeding source $[3,16]$.

The first challenge in the management of these cases is in the differential diagnosis of acute hemorrhagic abdomen in a cirrhotic patient. We suggest a flowchart based on the analysis of all the published cases related to intraperitoneal varices and a review of the articles related to the other causes of hemoperitoneum in cirrhotic patients (Figure 2).

The paracentesis with $\mathrm{Ht}$ over $5 \%$ is a precise indicator of intra-abdominal bleeding that can dimish the risk of unnecessary laparotomies [2]. It may be repeated in another site to exclude a punction accident and has rarely been to relate to hemorrhagic complications [16].

Once the bleeding in a cirrhotic patient was identified, the diagnostic orientation is made on differing HCC rupture, bleeding intra-abdominal varices, vascular causes such as aorta's aneurism, and gynecological causes.

We suggest checking the dosage level of HCG in women, followed by Abdominal Duplex Scan in both sexes as the first diagnostic step. Duplex scan can provide information on the Aorta and its branches, the abdominal collateral circulation, the patency of the Portal Vein, hepatic nodules and tumors, and the ovaries.

Computerized tomographic scanning was suggested by Bataille et al. [15] and Goldstein et al. [5] as the first diagnostic approach for excluding rupture of hepatocellular carcinoma and all other causes. It is, though, more expensive than the Duplex Scan, and it is not always available in all emergency services. On the other hand, it provides more detailed information on other acute hemorrhagic abdomen.

Arteriography has proved to be an inefficient investigation for diagnosis and treatment of retroperitoneal bleeding varices. It postpones the surgical treatment [14], the only one 


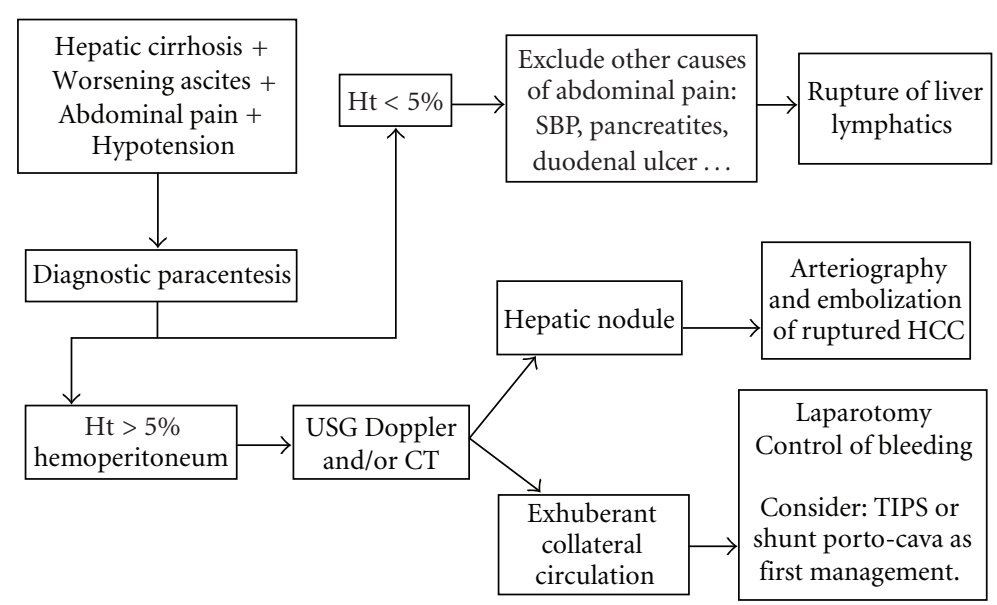

FIGURE 2: Fluxogram for diagnosis and treatment of hemoperitoneum in cirrhotic patients. SBP: Secondary bacterial peritonitis; Ht: Hematocrit; US: Ultrassonography; CT: Computerized abdominal tomography; HCC: Hepatocellular carcinoma; TIPSS: Transjugular intrahepatic portosystemic shunt.

that has been effective in these cases. Thus, it is very important to notice that arteriography has a fundamental role in the treatment of the rupture of hepatocellular carcinoma, which is the main differential diagnosis as mentioned before.

The fundamental treatment of variceal bleeding is the ligation of the vessel. Nevertheless, the Surgical Portosystemic Shunt or the Transjugular Intrahepatic Portosystemic Shunt (TIPSS) must be considered for selected patients.

In the operation room, the decision of performing a Portosystemic shunt must take into consideration the patient's clinical condition and the time needed to perform the shunt. In unstable patients and with little hepatic functional reserve we strongly suggest not increasing the surgical time. However, multiple bleeding varices or the possibility of a new bleed should be analyzed in order to decide if the shunt must be performed.

TIPSS was not performed in any of the reported cases. Nevertheless, the way we understand its use for treatment of gastroesophageal varices can help us in treating variceal bleeding from the retroperitoneum. Therefore TIPSS can be used mainly for the patient's postoperatory when there is suspicion of a new bleeding, or for diminishing the portal tension in selected patients serving as a bridge for liver transplantation. Before deciding if the TIPSS will be performed, one must be aware of its contraindications and complications as bleeding, perforation of the liver capsule, and encephalopathy, among others.

\section{Conclusion}

Bleeding intraperitoneal varix is a rare complication of portal hypertension, but carries a high mortality rate. Nonetheless, the physician must know this condition, as the clinical suspicion is the only way of establishing an early diagnosis and indicating surgery at once, which is the only effective treatment.

We suggest a flowchart to optimize the treatment of the acute hemorrhagic abdomen in the cirrhotic patient.
Paracentesis followed by ultrassonography with Duplex Scan or Computerized Tomography seems to be the most important procedure for establishing the correct diagnosis of abdominal pain, distention, and shock. Thereafter, surgery must be performed as soon as possible in case of ruptured varices. Arteriography should be used when the suspicion is of rupture of hepatocellular carcinoma.

\section{References}

[1] H. Elis, P. W. W. Griffiths, and A. MacIntyre, "Hæmoperitoneum. A record of 129 consecutive patients with notes on some unusual cases," British Journal of Surgery, vol. 45, no. 194, pp. 606-610, 1958.

[2] E. A. Akriviadis, "Hemoperitoneum in patients with ascites," American Journal of Gastroenterology, vol. 92, no. 4, pp. 567575, 1997.

[3] L. Fox, S. A. Crane, C. Bidari, and A. Jones, "Intra-abdominal hemorrhage from ruptured varices," Archives of Surgery, vol. 117, no. 7, pp. 953-956, 1982.

[4] E. L. Armstrong, W. L. Adams, L. J. Tragerman, and E. W. Townsend, "The Cruveilhier-Baumgarten syndrome. Review of literature and report of two additional cases," Annals of Internal Medicine, vol. 16, pp. 113-151, 1942.

[5] A. M. Goldstein, N. Gorlick, D. Gibbs, and C. Fernández-del Castillo, "Hemoperitoneum due to spontaneous rupture of the umbilical vein," American Journal of Gastroenterology, vol. 90, no. 2, pp. 315-317, 1995.

[6] A. P. Ross, "Portal hypertension presenting with haemoperitoneum," British Medical Journal, vol. 1, no. 5695, p. 544, 1970.

[7] F. Léauté, E. Frampas, G. Mathon, J. Leborgne, and B. Dupas, "Hémopéritoine massif par rupture d'une varice intraabdominale," Journal de Radiologie, vol. 83, no. 11, pp. 17751777, 2002.

[8] S. Sprayregen, L. J. Brandt, S. Bohm, and R. Stechel, "Bleeding intraperitoneal varix. Demonstration by arteriography and successful treatment with infusion of vasopressin into the superior mesenteric artery," Angiology, vol. 29, no. 11, pp. 857861, 1978. 
[9] T. F. Shapero, R. H. Bourne, and R. G. Goodall, "Intra abdominal bleeding from variceal vessels in cirrhosis," Gastroenterology, vol. 74, no. 1, pp. 128-129, 1978.

[10] D. T. Lyon, A. G. Mantia, and T. T. Schubert, "Hemoperitoneum from a ruptured varix in cirrhosis. Case report and literature review," American Journal of Gastroenterology, vol. 71, no. 6, pp. 611-616, 1979.

[11] K. A. Fawaz, J. M. Kellum, and R. A. Deterling, "Intraabdominal variceal bleeding," American Journal of Gastroenterology, vol. 77 , no. 8, pp. 578-579, 1982.

[12] J. Miller and J. Dinnen, "Ruptured abdominal varix," The New England Journal of Medicine, vol. 278, no. 9, p. 508, 1968.

[13] K. Mall and H. Grundies, "Haemoperitoneum als Folge portaler hypertension," Medizinische Klinik, vol. 69, pp. 20752076, 1974.

[14] C. Tarbe De Saint-Hardouin, N. Peigney, L. Hannoun, et al., "Hémoéritoine par rupture de laveine ombilicale," Gastroentérologie Clinique et Biologique, vol. 12, pp. 501-502, 1988.

[15] L. Bataille, J. Baillieux, P. Remy, R.-M. Gustin, and C. Denié, "Spontaneous rupture of omental varices: an uncommon cause of hypovolemic shock in cirrhosis," Acta GastroEnterologica Belgica, vol. 67, no. 4, pp. 351-354, 2004.

[16] P. Puche, E. Jacquet, S. Jaber, et al., "Spontaneous haemoperitoneum due to a ruptured intra-abdominal varix with cirrhosis," Annales de Chirurgie, vol. 144, no. 2, pp. 157-159, 2007.

[17] S. R. Smalley, C. G. Moertel, J. F. Hilton, et al., "Hepatoma in the noncirrhotic liver," Cancer, vol. 62, no. 7, pp. 1414-1424, 1988.

[18] G. Luna, L. Florence, and K. Johansen, "Hepatocellular carcinoma. A 5 year institutional experience," American Journal of Surgery, vol. 149, no. 5, pp. 591-594, 1985.

[19] M. C. Kew and J. Hodkinson, "Rupture of hepatocellular carcinoma as a result of blunt abdominal trauma," American Journal of Gastroenterology, vol. 86, no. 8, pp. 1083-1085, 1991.

[20] M.-F. Chen, T.-L. Hwang, L.-B. Jeng, Y.-Y. Jan, and C.-S. Wang, "Surgical treatment for spontaneous rupture of hepatocellular carcinoma," Surgery Gynecology and Obstetrics, vol. 167, no. 2, pp. 99-102, 1988.

[21] M. Okazaki, H. Higashihara, F. Koganemaru, et al., "Intraperitoneal hemorrhage from hepatocellular carcinoma: emergency chemoembolization or embolization," Radiology, vol. 180, no. 3, pp. 647-651, 1991.

[22] B. E. Nelson, M. L. Carcangiu, and J. T. Chambers, "Intraabdominal hemorrhage with pulmonary large cell carcinoma metastatic to the ovary," Gynecologic Oncology, vol. 47, no. 3, pp. 377-381, 1992.

[23] J. M. Kosowsky and W. B. Gibler, "Massive hemoperitoneum due to rupture of a retroperitoneal varix," Journal of Emergency Medicine, vol. 19, no. 4, pp. 347-349, 2000.

[24] Z. Ben-Ari, A. P. McCormick, S. Jain, and A. K. Burroughs, "Spontaneous haemoperitoneum caused by ruptured varices in a patient with non-cirrhotic portal hypertension," European Journal of Gastroenterology and Hepatology, vol. 7, no. 1, pp. 87-90, 1995.

[25] W. Gross, H. Kaffarnik, and W. O. Strik, "Intraperitoneal hemorrhage due to liver cirrhosis," Munchener Medizinische Wochenschrift, vol. 105, pp. 529-530, 1963.

[26] H. Steiner, "Acute hemoperitoneum. Report on 140 cases of intra-abdominal massive hemorrhage," Schweizerische Medizinische Wochenschrift, vol. 96, no. 27, pp. 875-882, 1966.
[27] J. J. Rothschild, I. Gelernt, and W. Sloan, "Ruptured mesenteric varix in cirrhosis-unusual cause for hemoperitoneum," The New England Journal of Medicine, vol. 278, no. 2, pp. 9798, 1968.

[28] J. M. Philippe, E. Dusehu, and P. Fiévet, "Rupture of the varices of the colo-parietal ligament. Possible cause of hemoperitoneum in the cirrhotic patient," La Nouvelle Presse Medicale, vol. 6, no. 8, p. 659, 1977.

[29] E. Legue, L. de Calan, J. P. Ozoux, and J. Brizon, "Rupture of varices of the round ligament. Unusual cause of spontaneous hemoperitoneum in the cirrhotic patient," Presse Medicale, vol. 12, no. 47 , p. 3004, 1983.

[30] J. W. Jhung and T. S. Micolonghi, "Ruptured mesenteric varices in hepatic cirrhosis: a rare cause of intraperitoneal hemorrhage," Surgery, vol. 97, no. 3, pp. 377-380, 1985.

[31] K. Ragupathi, A. Bloom, and N. Pai, "Hemoperitoneum from ruptured omental varices," Journal of Clinical Gastroenterology, vol. 7, no. 6, pp. 537-538, 1985.

[32] B. Paizis, E. Krespis, A. Filiotou, P. Kalochairetis, and B. Golematis, "Rupture of a periumbilical vein causing hemoperitoneum in a cirrhotic patient," The Mount Sinai Journal of Medicine, vol. 53, no. 2, pp. 123-125, 1986.

[33] H. Sato, S. Kamibayashi, T. Tatsumura, and K. Yamamoto, "Intraabdominal bleeding attributed to ruptured periumbilical varices. A case report and a review of the literature," Japanese Journal of Surgery, vol. 17, no. 1, pp. 33-36, 1987.

[34] A. N. J. Graham, P. McAleese, and R. J. Moorehead, "Intraperitoneal rupture of ectopic varices-a rare complication of portal hypertension," HPB Surgery, vol. 7, no. 4, pp. 315-318, 1994.

[35] M. Molina-Perez, F. Rodriguez-Moreno, E. Gonzalez-Reimers, et al., "Haemoperitoneum secondary to rupture of retroperitoneal variceal," HPB Surgery, vol. 10, no. 5, pp. 329-331, 1997.

[36] T. M. Ramchandran, A. John, S. S. Ashraf, M. S. Moosabba, P. V. Nambiar, and R. Shobana Devi, "Hemoperitoneum following rupture of ectopic varix along splenorenal ligament in extrahepatic portal vein obstruction," Indian Journal of Gastroenterology, vol. 19, no. 2, p. 91, 2000.

[37] J. P. Moreno, R. Piña, F. Rodríguez, and O. Korn, "Spontaneous hemoperitoneum caused by intraabdominal variceal rupture in a patient with liver cirrhosis. Clinical case," Revista Medica de Chile, vol. 130, no. 4, pp. 433-436, 2002.

[38] E. C. Chu, W. Chick, D. J. Hillebrand, and K.-Q. Hu, "Fatal spontaneous gallbladder variceal bleeding in a patient with alcoholic cirrhosis," Digestive Diseases and Sciences, vol. 47, no. 12, pp. 2682-2685, 2002. 


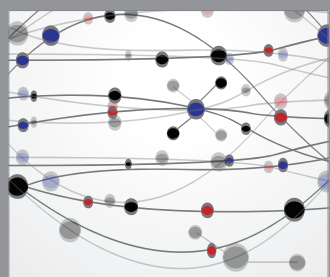

The Scientific World Journal
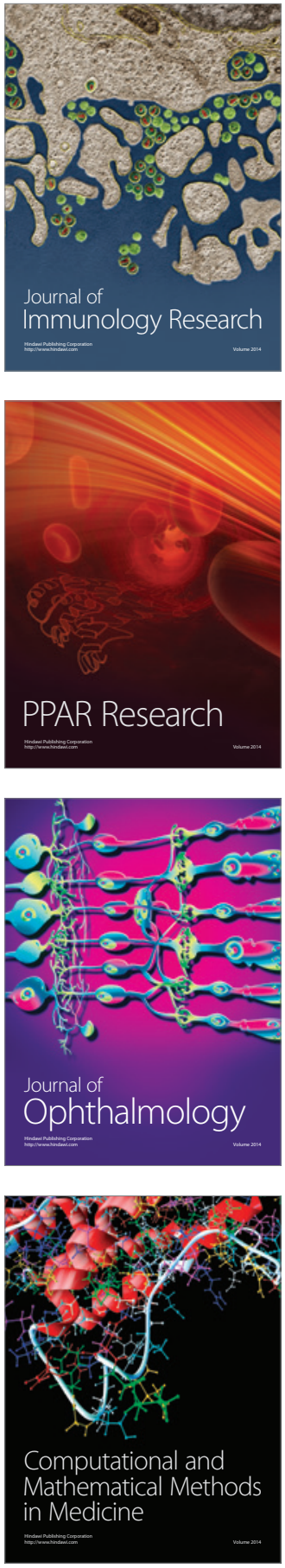

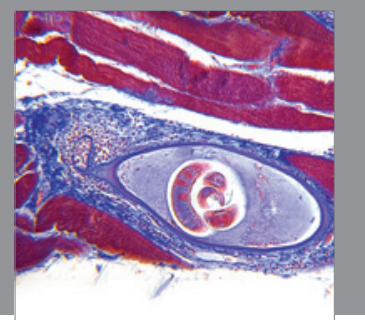

Gastroenterology

Research and Practice
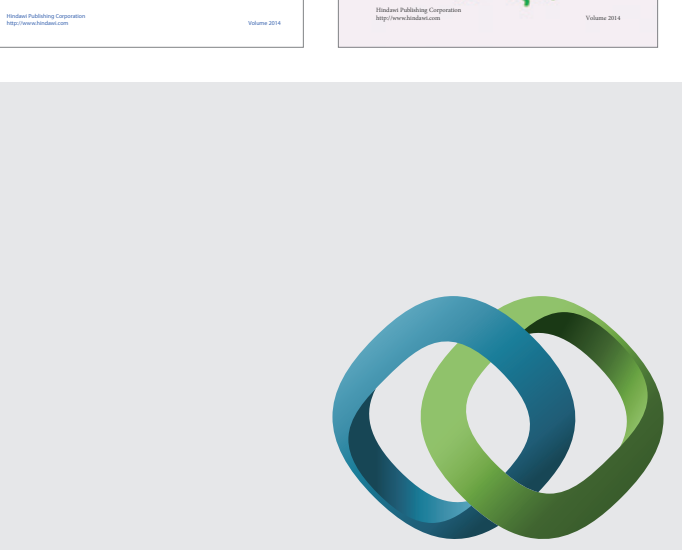

\section{Hindawi}

Submit your manuscripts at

http://www.hindawi.com
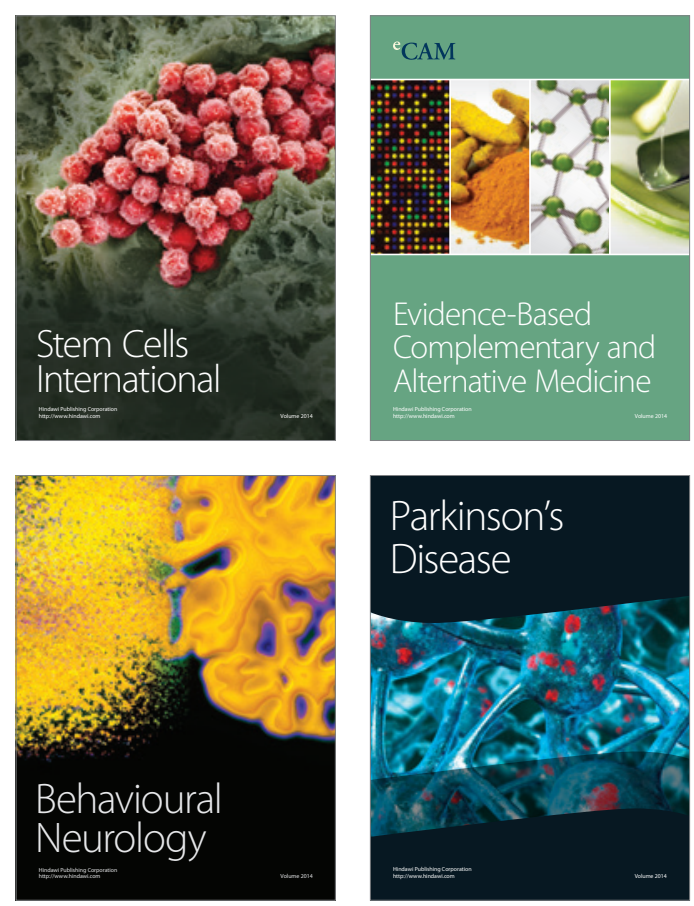

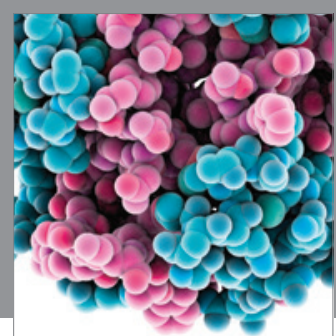

Journal of
Diabetes Research

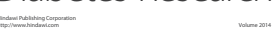

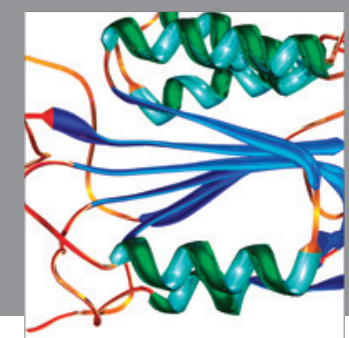

Disease Markers
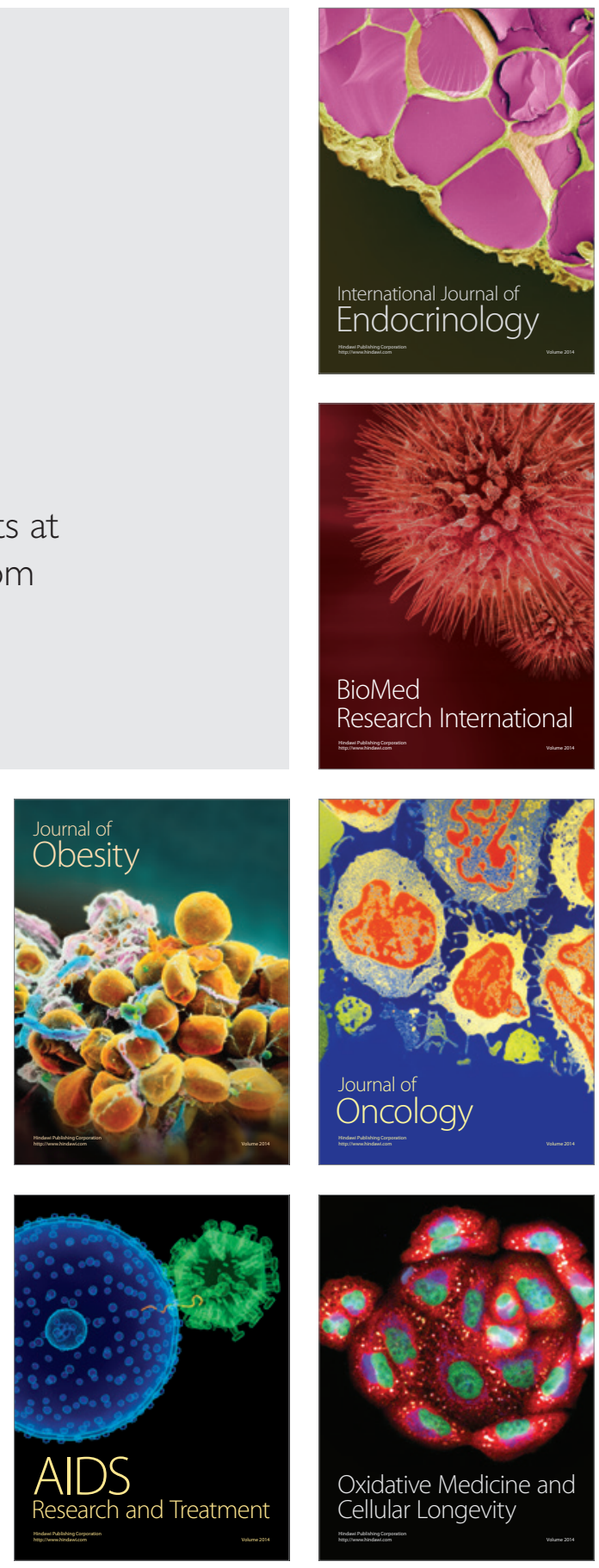